Crítica y Derecho

Revista Jurídica

e-ISSN 2737-6281 / p-ISSN 2737-629X

http://revistadigital.uce.edu.ec/index.php/criticayderecho/index

\title{
Derechos en el contexto de la pandemia de la COVID-19
}

La COVID 19 y el sistema carcelario del ecuador: Diagnóstico en épocas de pandemia

COVID 19 and the Ecuadorian prison system: Diagnosis in times of pandemic

\section{Mauricio Enrique Pacheco}

Doctor dentro del Programa de Doctorado en Estado de Derecho y Gobernanza Global por la Universidad de Salamanca

Profesor titular en la Facultad de Jurisprudencia de la Universidad Central del Ecuador. Ecuador.

Email: maurpacheco@hotmail.com

ORCID: https://orcid.org/0000-0003-3727-9300

\section{Brenda Viviana Guerrero Vela}

Doctora en Jurisprudencia y Abogado de los Tribunales y Juzgados de la República

Directora del Posgrado de la Facultad de Jurisprudencia. Universidad Central del Ecuador. Ecuador.

Email: bvguerrero@uce.edu.ec

ORCID: https://orcid.org/0000-0001-9647-0143 



\section{RESUMEN}

El fenómeno sanitario del COVID 19 ha constituido una de las afectaciones más grandes que ha tenido la sociedad mundial después de la segunda guerra mundial. El nivel de afectación ha sido general porque no existe una sociedad en el mundo que no haya sido afectada por las consecuencias del virus. Todos los países desde sus propias particularidades han dado respuestas que con el pasar de los meses y la acentuación del nivel de contagios y de muertes se homogenizaron relativizando los efectos en la sociedad moderna donde las primeras víctimas fueron los ancianos, las personas que vivían en condiciones sanitarias precarias, en aquellas personas con enfermedades terminales 0 de alto riesgo y en las personas que se encuentra recluidas en los centros de privación de libertad. La realidad frente a este problema es preocupante. La pandemia nos encuentra con un sistema penitenciario colapsado por la falta de salubridad, por la ausencia de control estatal al interior de las cárceles y por un hacinamiento escandaloso producto de una política procesal penal y penitenciaria de mano dura que es renuente a aceptar las recomendaciones realizadas por organismos internacionales para disminuir estos fenómenos que salvarán vidas de privados de libertad. Este artículo devela la forma cómo el Estado ecuatoriano desarticula los compromisos adquiridos y estas recomendaciones que aparenta cumplirlas pero que en verdad no las implementa de la forma efectiva y eficaz.

Palabras clave: hacinamiento, COVID-19, personas privadas de libertad, sobrepoblación carcelaria, motines, prelibertad.

\section{ABSTRACT}

The health phenomenon of COVID 19 has constituted one of the greatest impacts that world society has had after the Second World War. The level of affectation has been general because there is no society in the world that has not been affected by the consequences of the virus. All countries from their own peculiarities have given answers that with the passing of the months and the accentuation of the level of infections and deaths, they became homogenized, relativizing the effects in modern society where the first victims were the elderly, people who lived in conditions precarious health, in those with terminal illnesses or high risk and in people who are confined in the detention centers. The reality in front of this problem is worrying. The pandemic finds us with a prison system collapsed due to the lack of sanitation, the absence of state control inside the prisons and scandalous overcrowding as a result of a heavy-handed criminal and prison procedural policy that is reluctant to accept the recommendations made by international organizations to reduce these phenomena that will save the lives of those deprived of liberty. This article reveals the way in which the Ecuadorian State disarticulates the acquired commitments and these recommendations that it appears to fulfill but does not actually implement them effectively and efficiently.

Keywords: overcrowding, COVID-19, people deprived of liberty, prison overcrowding, riots, pre-release

\section{INTRODUCCIÓN}

El Estado con estatus de garante de las condiciones de vida de las personas privadas de libertad en los centros carcelarios del país le implica una gran responsabilidad que 
no puede ser evitada a pretexto de invocar conceptos de soberanía que ya han sido superados debido a la preeminencia de las obligaciones que tienen los Estados a los convenios y tratados internacionales firmados por el Ecuador y que están por sobre cualquier consideración de carácter político interno. Pero este compromiso externo e interno tiene en el gobierno altos componentes de resistencia muy cuestionables que frente a una crisis desatada por la pandemia del COVID 19 deberían salir de la agenda reservada de la política interna del país. Dar un marco de apariencia de cumplimiento a los compromisos adquiridos por el Estado en materia de derechos humanos no es una línea de comportamiento acorde con el respeto al principio de la dignidad humana y peor cuando se ejecutan ciertos hechos muy indicativos de una conducta aparentemente imperceptible de ir en contra corriente de lo que la razón y el principio de humanidad exigen. Este artículo pretende mostrar la forma solapada cómo el gobierno nacional y el estado ecuatoriano al contrario de lo que las organizaciones internacionales como la ONU y la OEA, y de que los máximos organismos de justicia, como la Corte Constitucional y Corte Nacional de Justicia, en sus resoluciones, han exigido y sugerido eliminar el hacinamiento y reducir la propensión del sistema penal en la aplicación de la privación de libertad tanto en el ámbito de las condenas como en calidad de medida cautelar, dado el peligro advertido por aquellos organismos de disminuir las condiciones que desde antes son vulnerables e intolerables de los privados de libertad en los centros de encarcelamiento.

El incremento en la vulnerabilidad de la población carcelaria y de otras personas privadas de libertad durante la pandemia de COVID 19 exigen del Estado la implementación de todas las medidas de salud pública acordes a las particularidades de este sector de la población consideradas como comunidades vulnerables por los múltiples estudios realizados por expertos sanitarios tanto nacionales como internacionales. Subrayamos la necesidad de reducir al mínimo la aparición de esta enfermedad en esos entornos y de velar por que se apliquen medidas preventivas adecuadas destinadas a anticipar brotes importantes de esta calamidad y en las que se tenga en cuenta la perspectiva de género y el respeto a los derechos humanos.

\section{DESARROLLO}

\section{Hacinamiento y sobrepoblación}

El fenómeno carcelario del hacinamiento presente en casi todos los centros de detención en el país revela una cruda realidad que pone en peligro la salud, la seguridad y la dignidad humana de quienes son sus usuarios evidenciando que ni aún con la aplicación inmediata algún paliativo sanitario se puede disminuir los letales efectos del COVID 19. Queda latente la posibilidad cierta de un contagio mayor y multiplicador de propagación social. La reducción al mínimo del espacio físico y social de movilización y estadía en las cárceles del país, como lo definimos en forma muy elemental al hacinamiento, supone un obstáculo infranqueable a la prevención, preparación y respuesta que debemos tener frente a esta enfermedad. Una de las medidas que la OMS sugiere es la instrumentalización de políticas limitativas y reduccionistas de la privación de libertad, especialmente la preventiva, como última opción ante una realidad que revela, según cifras oficiales, un hacinamiento cercano al $40 \%$ en los centros de privación de libertad.

En este contexto, parte de la solución puede venir desde las decisiones judiciales orientadas a la liberación de los estados de privación de libertad de quienes han porcentualmente sus condenas y están en condiciones de acogerse a los beneficios establecidos en la ley, concretamente en el COIP. Estas políticas bien pueden ser 
parte de un plan sugerido internacionalmente de liberación controlada de un buen porcentaje de reclusos que tienen un mayor riesgo de contagio del COVID 19, incluidas las personas mayores de 65 años, personas con afecciones preexistentes y también los reclusos que han sido condenados por delitos menores y que no representen un riesgo mayo para la seguridad pública, con preferencia a quienes forman parte de los grupos vulnerables.

Lastimosamente el poco peso político y la mayor vulnerabilidad de los detenidos frente a las medidas de prevención en entornos sociales de privación de libertad hacen que cualquier política estatal y preventiva sea de difícil cumplimiento. Incluso las recomendaciones más elementales y de fácil ejecución como la higiene de manos y el distanciamiento social, son de difícil implementación en entornos sociales en donde el Estado ni siquiera puede atender la provisión de insumos básicos como pasta dental, jabón, mascarillas y alcohol, insumos que por lo menos eran atendidos por los entornos familiares de los presos pero que dejaron de hacerlo por la prohibición de las visitas a los centros carcelarios.

Las propias autoridades estatales reconocen la existencia de un nivel de hacinamiento considerable, o sea, un nivel de contacto físico permanente entre reclusos con una potencialidad de contagio considerable lo que hace que la tasa de infección sea mucho más alta de aquella que podemos encontrar en el resto de la población en general. Las políticas de prevención y control sanitario penitenciario deben prioriza el acceso a servicios de salud mínimos para el tratamiento preventivo del COVID 19 sin olvidarnos de las otras enfermedades letales que han sido invisibilizadas pero que conviven desde hace décadas con la población carcelaria, como son el VIH, tuberculosis, hepatitis y dependencia de opioides, así como también las condiciones igual de vulnerables del sector compuesto por todos los funcionarios, trabajadores, profesionales de la salud y proveedores de servicios. En este sentido, las orientaciones sobre las actuaciones emergentes que las autoridades el Estado deben implementar están previstas en los principios establecidos por indicadores normativos que constan en la misma Constitución y en las disposiciones de los instrumentos internacionales emanados de la ONU, como son las recomendaciones de la Organización Mundial de la Salud (OMS), las Reglas Mínimas para el Tratamiento de los Reclusos de las Naciones Unidas (Reglas Nelson Mandela) y en las innumerables políticas sanitarias que existen en el escenario mundial.

El efecto movilizador que la pandemia del COVID 19 ha generado en el Ecuador incluye una considerable cantidad de personas individualizadas o en agrupaciones en las que todas coinciden en un punto de encuentro que es la preocupación por la respuesta sanitaria estatal caracterizada como desatinada y con un alto contenido de carácter político. Más aún cuando se trata de la atención a la situación en la que se encuentran ciertos sectores de la población que tanto en el aspecto sanitario como social son considerados muy vulnerables, a veces indeseables, como es el caso de las personas privadas de libertad por condena o por prevención.

Varias organizaciones mundiales, incluida la Organización Mundial de la Salud OMS, en forma permanente recuerdan a los Estados el papel garantizador de los derechos de los privados de libertad y de los compromisos asumidos en los convenios internacionales, entre ellos, el de facilitar los mecanismos legales y políticos que les permitan regresar al mundo exterior para afrontar el peligro de la pandemia con mayores garantías y posibilidades de no salir letalmente afectados.

Mencionamos que en el Ecuador existen aproximadamente 40.000 personas privadas de libertad que permanecen en los centros carcelarios y que antes de la 
pandemia ya atravesaban por una crisis derivada del déficit sanitario y de seguridad con elevado saldo de reclusos con enfermedades y problemas de la salud graves.

Las políticas recomendadas por los organismos internacionales aparentemente tuvieron eco en el gobierno del Ecuador porque hasta abril del 2020 han liberado a 808 presos por la emergencia por COVID 19 como contribución a la eliminación del hacinamiento carcelario. Otra información da cuenta de que han sido liberados 577 presos beneficiarios por el cumplimiento integral de la pena, por cambio a régimen semiabierto, beneficio de prelibertad, sustitución de la prisión preventiva. Igualmente 364 personas detenidas por deudas por pensión alimenticia recobraron la libertad por esta misma razón incluso sin necesidad de audiencia. Lo que no denotan las estadísticas es que se olvidaron extender la libertad a personas que sin estar en las condiciones arriba expuestas son extremadamente vulnerables por su condición personal, su edad y su estado de salud por definición precarios dado el entorno de reclusión, probablemente por aspectos de carácter político debido a un posible beneficio a favor de exautoridades actualmente detenidas y condenadas.

Para el 8 de abril del 2020 las autoridades estatales reconocieron que pese a estas liberaciones el hacinamiento no se ha reducido en las 59 cárceles del país y los exactamente 39.743 presos tienen una tasa de hacinamiento del $40 \%$. Esto quiere decir que el número de detenidos en exceso alcanzan la cifra de aproximadamente 12.000 ciudadanos de los cuales los 808 liberados no representan sino apenas el $2 \%$ del total, cifra que en ningún contexto representa un porcentaje que denote un alivio al problema del hacinamiento. Las expectativas de que se liberen a otros 470 detenidos no hacen sino subir el porcentaje de liberados al 3\%. Sin embargo, las cifras oficiales no indican que existen 1024 personas han sido detenidas por incumplir el decreto 1017 que instauró el estado de excepción y las medidas de restricción de movilidad en el país lo que paradójicamente es un indicativo de que las autoridades está desorientadas en la política carcelaria frente al COVID 19 y frente al hacinamiento.

En efecto, la sobrepoblación es producto de una pésima administración del sistema de cumplimiento de las penas porque entre marzo y junio del 2020 se liberan a 971 presos por cumplimiento de las dos quintas partes de la pena, es decir aplicando el sistema de prelibertad previsto en el Código Orgánico Integral Penal, liberación en la que la actividad estatal y la única contribución del sistema penal es haber agilitado la concesión de un derecho previsto en la norma penal con anterioridad y que únicamente restringía su concesión a los internos que hayan fugado o intentado fugarse tal como lo establecía el anterior Artículo 699 del COIP.

Lastimosamente, la característica de la política penal y penitenciaria del actual régimen es la ampliación del marco punitivo a través de las reformas penales como respuesta a los problemas de inseguridad generados por la deplorable situación económica. En este sentido, la actitud estatal de regresar a ver a otro lado cuando los organismos internacionales sugieren algo en materia de derechos, ha sido evidente descubriendo a un país reacio a cumplir con estas condonaciones a quienes cumplimiento la pena y deben reintegrarse a la sociedad. El Estado no dimensiona las pretensiones de los reclusos y no tiene claro que lo que la comunidad penitenciaria busca no es un acto de humanidad frente a los efectos del COVID 19, lo que simplemente quieren es el cumplimiento de la ley que establece claramente los mecanismos de concesión de las prelibertades sin condicionamiento alguno.

\section{Un Estado reticente al principio de humanidad}

El Estado ecuatoriano para evitar la presión internacional por las inobservancias a las recomendaciones realizadas y seguir siendo, al mismo tiempo, fiel a su política 
que prioriza la seguridad mediante una política penitenciaria de mayor retención consistente en evitar cumplir con la ley y mantener su conducta de restricción de derechos a la libertad de los PPL que quieren acceder a este sistema de régimen abierto, el gobierno actual introduce en las Reformas al Código Orgánico Integral Penal, Registro Oficial No. 107- Martes 24 de diciembre de 2019 Suplemento y vigente desde el 24 de junio del 2020, la sustitución del mismo Artículo 699, antes mencionado, por otro artículo con la misma numeración que amplía el universo de prohibiciones para que casi la totalidad de los PPL no puedan acceder a estos beneficios por el cumplimiento del $80 \%$ de la pena. Se niega este derecho para quienes han cometido los delitos de asesinato, femicidio, sicariato, delitos contra la integridad y libertad personal con resultado de muerte, robo con consecuencia de muerte, delitos contra la integridad sexual y reproductiva, trata de personas y tráfico ilícito de migrantes, delitos de violencia contra la mujer o miembros del núcleo familiar, cohecho, concusión, peculado, enriquecimiento ilícito, lavado de activos, enriquecimiento privado no justificado, delitos de tráfico ilícito de sustancias catalogadas sujetas a fiscalización en alta y gran escala, terrorismo, delincuencia organizada, abigeato con resultado de muerte y graves violaciones a los derechos humanos y delitos contra el derecho internacional humanitario. Curiosamente no se encuentran impedidos los condenados por tráfico de influencias ni asociación ilícita ni delincuencia organizada que son aquellos por los cuales se encuentran condenados algunos jerarcas de la administración pública anterior por actos de corrupción.

En otras palabras, gracias a la reforma estos exfuncionarios sí podrían solicitar libertad controlada porque aquellos delitos no son por los que se niega el acceso al régimen de prelibertad, reforma que deja serias sospechas cuando la asociación ilícita, por ejemplo, es un delito castigado con una pena mayor que otros delitos que sí constan en los delitos restringidos por la reforma penal, como es el enriquecimiento privado no justificado que tiene una pena privativa de libertad de 3 a 5 años.

La pandemia del COVID-19 fue funcionalizada políticamente para introducir reformas penales que niegan la prelibertad en decenas de infracciones (antes no había ninguna restricción) tomando como referencia el tipo de delito y no el nivel de peligrosidad de cada recluso, criterio que sí es utilizado al interior de los centros de privación de libertad para la ubicación en los pabellones. Muchos países aplican el principio de otorgar libertades a los PPL en función de otras variables cuya evolución se encuentra debidamente registrada en las carpetas individuales de los detenidos y que de alguna manera permiten un pronóstico de comportamiento que no se considere peligroso, aunque nada se pueda garantizar absolutamente, reservándose para aquellos que hayan cometido delitos execrables como homicidios, asesinatos y violaciones sexuales en general.

No se logra entender el objeto de negar una prelibertad a quienes están en el derecho de solicitarla y que el Estado debe conferirlas no como una concesión generosa sino como un derecho que sirve para disminuir el hacinamiento carcelario que tiene una elevada sobrecarga en la cantidad de reclusos en un escenario de por sí peligroso por las deplorables condiciones de vida. No obstante, en contra de las sugerencias de la OMS, la Comisión Interamericana de los Derecho Humanos, de la misma Corte Constitucional del Ecuador y la Corte Nacional de Justicia, las autoridades gubernamentales y el Estado del Ecuador amplía el abanico de restricciones por las que se debe negar de plano esta concesión con el objetivo político de mantener el mayor número de condenados en el encierro carcelario potenciando el contagio de esta peligrosísima enfermedad. Lastimosamente olvidaron que para los actuales presos no están vigente estas reformas porque se acogerán al 
principio de favorabilidad constitucional y legal que permitirían a los reclusos se les aplique la ley más favorable, como es el antiguo artículo 699 del COIP.

La política carcelaria en la visión del gobierno central se limita a la entrega de estadísticas mediante las cuales se ha reducido el índice de hacinamiento en porcentaje del $10 \%$ aproximadamente para situarse en el rango del $27 \%$. Lo que no dice cuál es el porcentaje de reducción de privados de libertad, no del hacinamiento. Si se han dado más de 2.000 soluciones carcelarias éstas se refieren a las que no entraron a la cárcel, sino que fueron sustituidas con las medidas cautelares dentro de los procesos penales pretendiendo contabilizar presos que aún no eran presos para forzar la rebaja o reducción del índice de hacinamiento. Pero la reducción del número total de privados de la libertad sigue siendo una cantidad demasiado baja en comparación de los actuales 38.000 PPL teniendo en cuenta que el gobierno correísta inició con 12.000 presos y que luego de un descomunal incremento de encarcelados, en aproximadamente en el $300 \%$, se llegó a las cifras que actualmente tenemos. La respuesta es obvia si averiguamos las razones de este incremento; se debe a la política de mano dura con el sector más débil de la población, con la criminalización de bagatelas, con la política de coacción y presión a los jueces para que se sometan a los designios de mano dura, fidelidad al partido y venganzas personales, agravadas aún más contra aquellos jueces que dentro del marco de la ley flexibilizaban la toma de medidas privativas de libertad.

El Estado mantiene la idea y el convencimiento de que la pandemia del COVI 19 en los centros de privación de libertad junto con las medidas adoptadas para simular un control del hacinamiento y sobrepoblación son necesarias para el mantenimiento de un dominio del Estado al interior de los centros de privación de libertad. Sin embargo, las cosas no son como quieren que parezcan. Ciertos acontecimientos sucedidos durante este año 2020 son indicativos de algo que venimos anticipando desde hace algún tiempo y que desnudan la verdadera intención del gobierno que es la de no reducir el número de reclusos que se encuentran en las cárceles del Ecuador manteniendo una estructura administrativa y legal que fortalece el hacinamiento y la sobrepoblación.

En efecto, las reformas publicadas en el Registro Oficial No. 107-martes 24 de diciembre de 2019 Suplemento, contribuyen directamente con el sistema de hacinamiento carcelario porque del análisis de las medidas adoptadas en esta reforma se puede concluir que el gobierno prioriza el tema de la seguridad interna y no el tema de la rehabilitación efectiva al introducir un elemento de retención, incluso desautorizado por otras legislaciones penales, como es la reincidencia.

El tema de la reincidencia es de por sí inconstitucional, porque nadie puede recibir una pena por su condición de reincidente en virtud del principio de culpabilidad, de prohibición del non bis ídem, del principio de personalidad de las penas, por el derecho penal de acto y no de autor, por violar el principio de legalidad, porque recibir un tercio más de la pena por reincidente atenta contra los estipulado en las garantías constitucionales y el artículo 5 del COIP.

Sin embargo, la reforma dice que los reincidentes permanecerán más tiempo en las cárceles, en un tercio adicional de la pena, por delitos que se vuelvan a repetir en menoscabe del mismo bien jurídico y no en función del mismo delito, con lo que amplía enormemente los casos de condena por reincidencia. Pero además introduce un elemento propio del derecho penal de autor porque la reforma del artículo que agrega al artículo 2 del COIP expresa que la tutela judicial efectiva sirve para garantizar la prevención de la reincidencia penal. Frente a disposiciones como la presente nos preguntamos con una muestra de preocupación ¿cómo se puede 
prevenir la reincidencia teniendo al preso más tiempo en la cárcel, contribuyendo al a la agravación de un fenómeno que precisa y aparentemente se han comprometido a disminuir? La reincidencia se combate realizando una verdadera política de prevención de cuyas ejecutorias el Estado es el único responsable. No puede trasladar su irresponsabilidad por no rehabilitar a un condenado al mismo condenado que no ha sido rehabilitado por el estado después de pasar mucho tiempo en la cárcel. Es un lavado de manos propio del derecho penal simbólico y populista.

En la misma línea, el discurso estatal insiste en que están desplegando una política penitenciaria y penal que recoge plataformas de sugerencias internas y externas que exigen al Estado flexibilizar o minimizar exigencias legales y extralegales para la concesión de medidas que restrinjan la aplicación indiscriminada de la prisión de carácter preventivo. Dada la dependencia de los jueces en materia jurisdiccional de las políticas del Consejo de la Judicatura saben perfectamente que no pueden aperturarse para flexibilizar la permanencia de los reclusos en las cárceles porque al final de la jornada los jueces generalmente son sancionados y hasta destituidos por cumplir con lo que ordena la ley penal, o en su defecto, obtienen evaluaciones negativas.

En este mismo sentido se reformó el artículo 536 COIP que niega la posibilidad de solicitar una medida sustitutiva a la prisión preventiva de parte de quienes siendo aún procesados tengan el antecedente de ser reincidentes. No solo que trastoca en forma casi atrevida los principios más elementales del Derecho penal reconocidos por los más venerados penalistas de todo el mundo y que se encuentran previstos en casi todas las legislaciones del orbe. Reincidente es aquel que vuelve a cometer el mismo delito por el que nuevamente ha recibido sentencia condenatoria. No es reincidente el procesado que ha cometido un delito anterior sin siquiera haber recibido una nueva sentencia o condenado por segunda vez, sin embargo, y de acuerdo con los reformistas criollos, este tipo ya es un reincidente por lo que a criterio de la reforma implementada se niega el acceso al beneficio de la sustitución de la medida cautelar de prisión preventiva.

Esta reforma que regula la reincidencia viola un principio básico del proceso penal y es el principio de presunción de inocencia constitucional y legal al darle la calidad de reincidente por anticipado a quien tiene un segundo proceso olvidándose algo de elemental consideración: la reincidencia es una calidad que el juez le otorga al momento de dictar sentencia, no durante el proceso porque de hacerlo de esa manera están adelantando barreras punitivas en contra del procesado al adjudicarle un estatus que todavía no se verifica.

¿Decisiones como las analizadas realmente contribuyen a disminuir el nivel de hacinamiento en las cárceles del país? No y la respuesta es obvia, con esto se demuestra que la política penal-penitenciaria del Estado ecuatoriano en relación con la declaratoria de emergencia por el COVID 19 es contradictoria y populista que no contribuye al respeto a los derechos humanos de los privados de la libertad consagrados en los convenios internacionales sobre derechos humanos, en la Constitución de la República y en el COIP, artículo 5. Existe una discriminación por su condición de condenado o procesado y un atentado al principio constitucional y penal de la igualdad, afectando el espíritu del Artículo 22 del COIP que estipula que ninguna persona podrá ser sancionada por cuestiones de identidad, peligrosidad, 0 características personales.

\section{Violencia y descontrol}

¿Qué ha traído como consecuencia esta política de negar los derechos que les corresponden a los privados de la libertad e implementar una política de simulación 
de un sistema que en teoría acepta las recomendaciones de la OMS pero que en la realidad realiza exactamente todo lo contrario?

Las flagrantes contradicciones de las actividades estatales en el manejo de las cárceles en el país, desde el inicio de la pandemia, arrojan resultados escalofriantes. Con seguridad afirmamos que hasta hace poco tiempo no teníamos este tipo de acontecimientos pese a contar con un sistema penitenciario muy precario como el que se vivían en el ex penal García Moreno y en las cárceles de Cuenca y de Guayaquil. Las políticas actuales asentadas en la priorización de las medidas de seguridad y control penitenciario tienen enormes grietas generadas no por el control supuestamente riguroso que se ejerce en las cárceles porque sabemos que físicamente los presos están fuera del control interno del Estado que no ha podido implementar un sistema de seguridad al interior con resultados medianamente satisfactorios.

La imposibilidad del Estado por asumir el completo control físico dentro de los centros penitenciarios del país ha cimentado una política de compensación de control externo destinada a proporcionar un equilibrio al desbalance generado por la ausencia de la presencia total y determinante de la administración al interior de los centros. El control externo y las declaratorias de emergencia tienen como actividades centrales el negar en forma intimidante mediante expresiones autoritarias de poder el ingreso de familiares, personas visitantes y profesionales del derecho que son impedidos de prestar los servicios profesionales a los reos que lo necesiten. Atentan contra el legítimo derecho de defensa y contacto social propio de las prerrogativas que la norma constitucional y legal les otorgan a los reclusos.

Esta política anti-hacinamiento se verifica a través del retardo y de la negación de los casos de excarcelación aun cuando se cumplan los requisitos del sistema abierto y que otorgan el derecho a la prelibertad una vez cumplidas las exigencias de los Artículos 696 al 698 del COIP. Se suspenden los casos de excarcelación por cumplimiento del régimen abierto, al igual que los trámites de obtención de la prelibertad a quienes han cumplido los tres requisitos requeridos; se niega y se suspenden el régimen de visitas, volverlos reincidentes sin posibilidad de recobrar su libertad aun cuando hayan aprobado procesos de rehabilitación.

El factor generador de violencia en las cárceles proviene de la persistente y solapada negativa del sistema gubernamental de ser beneficiarios de políticas de flexibilización y de provisión de insumos médicos y sanitarios generados tanto por el problema del hacinamiento como por la pandemia ocasionada con el COVID 19. Antes del decreto de emergencia carcelaria los provisionamientos de insumos sanitarios los hacían generalmente los familiares de los reclusos que pese a ser objeto de tratos degradantes al momento en las instancias del ingreso a los centros de detención, cubrían una parte fundamental en la provisión de medicamentos que no lo hacía el Estado. Con la nueva declaratoria de emergencia el acceso de familiares y de los abogados defensores se han tornado imposibles y la carencia de insumos y materiales sanitarios en sus estándares mínimos tampoco ha sido cubierta por el Estado.

Las actitudes y procedimientos de las autoridades estatales sumado a la negativa de implementar mecanismos de recuperación de libertad mediante las medidas sustitutivas previstas en la ley constituyen un factor detonante de la generalizada violencia que tiene como escenario las cárceles del país. Debe entenderse que las respuestas mortalmente violentas no son sino señales de una gestión carcelaria deficiente que pretende encubrir los hechos derivando la responsabilidad a una simple lucha de bandas o mafias por el control de los reclusos. Lo que no dicen es que las 
demandas de los presos van en contra de todas las medidas implementadas y criticadas en este artículo que provocan desesperación en la mayoría de los reclusos que frente a la ausencia del contacto con los familiares proveedores de medicamentos y otras vituallas, se sienten desprotegidos del Estado. Lo grave es la ausencia de una política de diálogo y conciliación para que ambas partes puedan esgrimir la necesidad de ciertas medidas. Los hechos violentos que no logra decodificar el Estado han sido múltiples en el transcurso de este año 2020, veamos algunos hechos:

El Servicio Integral de Atención a Personas Privadas de Libertad reveló que el 20 de febrero del 2020 fueron muertos seis privados de libertad que se encontraban en los pabellones de mínima, mediana y máxima seguridad de la cárcel de Turi, en Azuay. Cuatro días después el Gobierno de Ecuador declaró el "estado de excepción" por 60 días en el sistema carcelario del país, Decreto Ejecutivo 741, firmado por el presidente Lenin Moreno, que fue extendido el 15 de julio por un mes más, mediante el Decreto Ejecutivo 823.

La respuesta del Estado desde la visión plana de la seguridad y la necesidad de la retoma del control fue evidente porque priorizó medidas de seguridad cristalizadas por el estado de movilización de la fuerza pública para el control del ingreso y egreso de las cárceles. La medida de financiamiento se implementa no para satisfacer las necesidades de los centros sino para cubrir el costo de la movilización de los militares y policías; suspenden el ejercicio del derecho a la inviolabilidad de correspondencia, libertad de información y libertad de asociación y reunión con atribuciones de revisar íntegramente la mencionada correspondencia. Es decir, se olvidaron de la esencia que tienen el fenómeno de la violencia intracarcelaria y de los derechos de los detenidos, no se habla sobre las medidas para implementar mecanismos de rehabilitación, de saneamiento, de programas de empleo y capacitación efectiva, de medidas alternativas, del problema de COVID19 y de políticas de ocupación del tiempo de los reclusos.

En el trascurso del estado de excepción se produjeron 14 asesinatos de internos, que antes del estado de excepción fueron apenas 7 muertes en todo el año 2019. El 12 de mayo varios privados de libertad agredieron a otro reo con golpes y más de 30 puñaladas riña que fue reprimida por la policía que al pretender dispersar causó la muerte de un reo en la cárcel de El Turi, en Cuenca. Antes, el 20 de enero hubo seis muertes en la misma cárcel en Cuenca. Los cuerpos estaban colgados de las literas.

Estos acontecimientos confirman una vez más que el estado no tiene control físico en las principales penitenciarias porque el 23 de julio de este año, el Servicio Nacional de Atención Integral a Personas Adultas Privadas de Libertad y Adolescentes Infractores (SNAI) otro reo fue muerto ahorcado en el pabellón de máxima seguridad del CRS Turi, ubicado en la ciudad de Cuenca, provincia de Azuay.

En la penitenciaría de la ciudad de Guayaquil en el mes de mayo del 2020 fueron muertos ocho presos y después de algunos días fue asesinado brutalmente el interno alias "el cubano" y el 15 de abril otro hecho dejó dos reos muertos. El 03/08/2020 tratan de controlar un motín tras la muerte de cuatro internos. El cuatro de agosto del 202011 presos son muertos en la Penitenciaría.

El policía detenido en la cárcel de Latacunga fue asesinado al interior del Centro de Rehabilitación Social (CRS) de Latacunga el 12 de febrero. En julio del 2020 otro motín estalla en la cárcel de Latacunga con exigencias de mayor respeto por los derechos de los recluidos y dejó dos presos asesinados, un policía herido y daños en diferentes áreas. Otro motín estalla en Latacunga el 16 de julio. El 25 de julio de los 2020 dos guardias penitenciarios son acribillados por supuestos sicarios en El Oro. El caso de la cárcel de la ciudad de Riobamba presenta situaciones que no difieren 
del resto de centros penitenciarios con altos niveles de contagio y desborde de la capacidad de atención. El sábado 8 de agosto del 2020 asesinan al israelí Shy Dahan en la Penitenciaría del Litoral y el 11 de agosto del 2020 dos internos murieron en la cárcel de Cotopaxi e inmediatamente el presidente declara el estado de emergencia en las cárceles del país.

Pero las estadísticas que no quieren actualizar son evidentes. Hasta el 20 de mayo del 2020 las estadísticas de contagios en el sistema penitenciario, según el Servicio de Atención Integral a Personas Privadas de la Libertad (SNAI) 526 personas dieron positivo en las cárceles del país: 45 guías y 481 presos. La cárcel de Ambato tiene el $87 \%$ de contagiados y de acuerdo con las pruebas realizadas por el Ministerio de Salud a 610 internos, 420 privados de la libertad tenían COVID 19. Este es el coctel letal de hacinamiento más pandemia y más ceguera de las autoridades penitenciarias que pueden estar explicando el nivel de violencia descrito y de necesidad de diálogo productivo entre los reclusos del país y las autoridades carcelarias.

Estos casos son ejemplificativos de la real situación que viven las cárceles del país agudizadas por la presencia de la pandemia del COVID 19 que contribuyó a agudizar un escenario de acentuados mecanismos de control violatorios de los derechos de los detenidos y que ratifica nuestra convicción de que si bien es cierto que existe una militarización al exterior de los centros de privación de libertad también hay que reconocer que el Estado no tienen presencia ni fuerza suficiente para controlar el ámbito interno. Si el Estado tiene la debilidad de carecer de control interno entonces no tiene el control de la integridad de los presos ni está en condiciones de ser garante de alguna política de rehabilitación. Se piensa desde el chip de la represión violenta y de la coacción psicológica a través de la restricción de derechos de los penitenciarios implementados como castigo que tiene su origen en la incapacidad de manejo del sistema general de rehabilitación por la vocación servicial de proyectar la figura de un modelo de mano dura en el combate a la delincuencia con fines electorales. Las falencias estatales en renunciar a los modelos de gestión internacional han generado un escenario de permanente rebelión interna y de descontrol.

\section{¿Qué hacer?}

De acuerdo con las Constitución de la República el estado ecuatoriano es garante de la seguridad y de la integridad de los privados de la libertad. Es decir, como garante debe controlar eficientemente los riesgos o peligros que se ciernan sobre su integridad sanitaria y personal de los internos. No es un mero enunciado que suele ser banalizado desde los medios de comunicación dándonos a entender que los problemas que se suscitan en las cárceles del Ecuador son hechos aislados y desconectados del ámbito de la administración carcelaria y cuya solución es el permanente traslado de reclusos a otro centro de reclusión bajo el justificativo falso pero permanentemente invocado de las bandas de criminales que gobiernan las cárceles. Todo crimen y desbande de los privados de libertad se reduce a conflictos en los "choneros" y las otras "bandas" que por arte de magia todavía no se logra identificarlas y procesarlas por la responsabilidad de las ejecuciones en el interior de los centros. Lo único cierto es que el discurso plano de la oficialidad pretende sin éxito alguno convencernos que el modelo de administración estatal de las cárceles del país es un modelo de perfección que no presenta fisura alguna excepto por el proceder aislado de los grupos de reclusos que demandan jerarquías entre ellos.

El Estado debe entender que existe un deber de cuidado que tiene el gobierno ecuatoriano en relación con los presos y que no solo se limita al ámbito territorial de los centros de detención. Debe además comprender que lo que sucede en estos 
centros tiene repercusión en el resto de la población porque no puede retener indiscriminadamente a los PPL no contagiados por el COVID 19 que reúnan los requisitos de prelibertad porque no están en capacidad de asegurar una mínima atención médica, aunque si tengan la obligación de cuidar al resto de la población del peligro que significa un PPL libre y contagiado.

Muchos ecuatorianos y tantas autoridades, incluidos los medios de comunicación, confunde que implementar una política de excarcelación equivale a una decisión de indulto o perdón. Pero no es así, la implementación de unas medidas que tienen la característica de ser temporales y transitorias por ser parte de una respuesta racional frente al estado de necesidad originado por la pandemia del COVID 19 que de no ser implementado y producirse el contagio en los centros de detención, vendría a ser una especie de condena a muerte para todos los reclusos dadas las paupérrimas condiciones de atención sanitaria que tienen. En ninguna de ellas existen quirófanos o por lo menos lugares aislados en los que puedan recuperare quienes resulten contagiados. Peor aún, el sistema de provisión de medicamentos es inexistente y nadie se puede curar sin que sean tratados con remedios que de una manera u otra sí los puede tener el resto de la población.

\section{CONCLUSIONES}

El Estado debe tomar de decisiones que están en la ley y en los principios constitucionales y legales preestablecidos más allá de los cálculos políticos que ello signifique. Es decir, por ejemplo, arresto domiciliario en los delitos menores, la implementación de medidas como el brazalete electrónico para cierto tipo de delitos, la caución como medida cautelar o de aseguramiento para quienes la puedan pagar, las medidas sustitutivas a la prisión preventiva desde el inicio del proceso y en los casos establecidos en la ley, la agilización de las concesiones de prelibertad, los indultos presidenciales que sin ser una medida que signifique numerosos beneficiarios, coadyuva en algo a la situación de liberar espacio para evitar el hacinamiento.

El COIP y la Constitución hablan sobre el principio de mínima intervención penal que no significa sino la presencia del Derecho penal y del poder punitivo del Estado orientado a perseguir y a castigar los casos de lesiones a importantes bienes jurídicos y desechar las intervenciones estatales penales en infracciones de poca importancia. En este contexto la prioridad del Estado es aplicar medidas que propongan como política enfocarse en la excarcelación de quienes no se encuentran condenados para que una vez liberados puedan defenderse en libertad, sin que esto implique una apertura total e indiscriminada que abarque a delincuentes encarcelados con serios indicios en la comisión de delitos graves. Se pide una política más humanitaria que dirigía la atención al interior de los centros carcelarios para crea la ventaja de estar en un entorno más liberado del hacinamiento

En otras palabras, enfocarse en aquellos que no están involucrados en delitos graves y en delitos no violentos, así como quienes tienen altas probabilidades de afecciones mortales como es el caso de los enfermos con problemas cardíacos, diabéticos, enfermos de SIDA, lupus, las mujeres con niños y otros pertenecientes a sectores vulnerables.

Las excarcelaciones no deben estar dirigidas a otorgar privilegios personalizados y con dedicatoria a ciertos personajes políticos acusados de delitos en contra de la administración pública porque estaría nuevamente en el plano de la politización de la justicia mediante presiones estatales para controlar la actividad jurisdiccional de los 
jueces, porque a futuro son tres cuestiones sobre las que se tienen que trabajar en relación con la política penitenciaria y judicial en nuestro país: la aplicación de un sistema más flexible de medidas alternativas a las medidas cautelares de prisión preventiva y a las condenas con penas privativas de libertad, con ello ganaríamos una batalla en contra del contagio de enfermedades contagiosas y con el hacinamiento carcelario.

\section{REFERENCIAS BIBLIOGRÁFICAS}

Akiyama MJ, Spaulding AC, Rich JD. Flattening the Curve for Incarcerated Populations Covid-19 in Jails and Prisons. N Engl J Med. 2020. doi: 10.1056/NEJMp2005687.

BBC News Mundo. Cárcel La Modelo: un motín en una prisión de Colombia deja 23 muertos en medio de la tensión por el coronavirus, UK: 2020, marzo 22. Disponible en: https://www.bbc.com/mundo/noticias-america-latina-519988003.

Caravaca-Sánchez F, Pastor-Seller E. Evaluación del impacto de las relaciones familiares sobre la salud de las personas privadas de libertad en España. Rev Esp Sanid Penit. 2020;22(1):33-40.

Dimensiones de derechos humanos en la respuesta al COVID-19. [Consultado 6 abril 2020]. Disponible en: https://www.hrw.org/es/news/2020/03/31/dimensiones-de-derechoshumanos-en-la-respuesta-al-covid-19\#_Toc36462297

Estadística penitenciaria. [Consultado 3 abril 2020]. Disponible en: http://www.institucionpenitenciaria.es/web/portal/documentos/estadisticas.html.

ElComercio.com. Ver el sitio https://www.elcomercio.com/actualidad/gobierno-excepcioncarceles-fuerzas-armadas.html

Europa Press. Una veintena de presos protagonizan un motín en la principal cárcel de Luxemburgo por las medidas contra el coronavirus. Madrid: 2020, marzo 26. Disponible en: https://www.europapress.es/internacional/noticia-veintena-presosprotagonizan-motin-principal-carcel-luxemburgo-medidas-contra-coronavirus20200326172131.html

España: las cárceles, una «olla a presión». [Consultado 6 abril 2020]. Disponible en: https://www.prison-insider.com/es/articles/espagne-las-carceles-una-olla-a-presion.

El rey de Marruecos indulta a 5.600 presos a causa del coronavirus, Madrid: 2020, marzo 5. Disponible en: https://elpais.com/internacional/2020-04-05/el-rey-de-marruecosabsuelve-a-5600-presos-a-causa-del-coronavirus.html

Gabinete de Prensa. Instituciones Penitenciarias distribuye 205 móviles para que los internos puedan comunicar con sus familias por videollamada. [Consultado 4 abril 2020]. Disponible en: http://www.institucionpenitenciaria.es/web/portal/Noticias/Noticias/noticia_0529.html

https://www.elcomercio.com/actualidad/muerte-presos-rina-carcel-cotopaxi.html. Si está pensando en hacer uso del mismo, por favor, cite la fuente y haga un enlace hacia la nota original de donde usted ha tomado este contenido.

López-Fonseca Ó. El virus salta los muros de la cárcel. El País, Madrid; 2020, abril 4. [Consultado 3 abril 2020]. Disponible en: https://elpais.com/espana/2020-04-03/elvirus-salta-los-muros-de-la-carcel.html

Liberación de presos iraníes por coronavirus excluye manifestantes arrestados, Barcelona: 2020, marzo 10. Disponible en: https://www.lavanguardia.com/vida/20200310/474080784282/liberacion-de-presosiranies-por-coronavirus-excluye-manifestantes-arrestados.html

Kinner SA, Young JT, Snow K, Southalan L, Lopez-Acuña D, Ferreira-Borges C, et al. Prisons and custodial settings are part of a comprehensive response to COVID-19. Lancet Public Health. 2020. pii: S2468-2667(20)30058-X. 
Yang H, Thompson JR. Fighting covid-19 outbreaks in prisons. BMJ. 2020;369:m1362. doi: 10.1136/bmj.m1362. 